\title{
COMPARATIVE ANALYSIS OF PENETRATING AND NON-PENETRATING GLAUCOMA SURGERY IN PRIMARY OPEN ANGLE GLAUCOMA
}

\author{
Sudhir Sudhakar Pendke1, Sanchit Satish Bhalgat ${ }^{2}$
}

${ }_{1}^{1}$ Associate Professor, Department of Ophthalmology, Indira Gandhi Government Medical College Nagpur, Maharashtra University of Health Sciences, Nasik, India.

2MBBS Student, Department of Ophthalmology, Indira Gandhi Government Medical College Nagpur, Maharashtra University of Health Sciences, Nasik, India.

\begin{tabular}{l}
\hline ABSTRACT \\
\hline OBJECTIVES \\
Purpose analysis of safety and efficacy of Non-Penetrating Glaucoma Surgery (NPGS) for control and maintenance of intraocular \\
pressure as compared to penetrating glaucoma surgery in Primary Open Angle Glaucoma (POAG) patients.
\end{tabular}

\section{DESIGN}

A hospital based randomized study. Participants 70, eyes of 70 POAG patients, 35 of which underwent NPGS and the remaining underwent Trabeculectomy surgery.

\section{MATERIALS}

NPGS and trabeculectomy was performed by standard surgical procedures after recording routine preoperative data. Patients were divided into 2 groups depending on the procedure they underwent. All patients were followed up after 1 week, 1 month, 3 months, 6 months and 12 months. Post-operative success was defined as IOP $<21 \mathrm{mmHg}$ at 1 month in absence of additional antiglaucoma medication or other treatment.

\section{RESULTS}

A significant reduction in intraocular pressure was observed post-surgery in both groups, changing from a preoperative mean of $31.09 \pm 7.37 \mathrm{mmHg}$ and $29.26 \pm 7.10 \mathrm{mmHg}$ to a postoperative mean of $15 \pm 3.06 \mathrm{mmHg}$ and $14.85 \pm 4.22 \mathrm{mmHg}$ respectively $(\mathrm{P}<0.001)$ at 12 months for trabeculectomy patients. It was seen that there was approximately constant reduction in all ranges of IOP, while for NPGS patient's best control in IOP was seen between at preoperative IOP between 21 to $30 \mathrm{mmHg}$. There was a significant difference in complications between two groups and the NPGS group had significantly less number of complications than the trabeculectomy group $(p<0.05)$. However, the trabeculectomy group had a significantly lesser failure rate as compared to the NPGS group $(\mathrm{p}<0.05)$.

\section{CONCLUSION}

Trabeculectomy though more effective for higher preoperative IOP, range is associated with greater risk of complications and hence for IOP range between 21 to $30 \mathrm{mmHg}$, NPGS would be the surgery of choice due to its equivalent efficacy and much greater safety standards.

\section{KEYWORDS}

Non-penetrating Glaucoma Surgery, Trabeculectomy, Non-invasive, Effective, Safe.

HOW TO CITE THIS ARTICLE: Pendke SS, Bhalgat SS. Comparative analysis of penetrating and non-penetrating glaucoma surgery in primary open angle glaucoma. J. Evolution Med. Dent. Sci. 2016;5(35):1963-1968, DOI: 10.14260/jemds/2016/464

\section{INTRODUCTION}

For many decades now, Trabeculectomy has been the surgery of choice in primary open angle glaucoma. Its high efficacy overshadowed its common but not so serious complications in the absence of a comparably effective less invasive procedure. With the advent of minimally invasive procedures in every field of medicine, non-penetrating glaucoma surgery is the alternative ophthalmologists are opting due to its high safety profile without compromising the efficacy seen with trabeculectomy.

Financial or Other, Competing Interest: None.

Submission 16-01-2016, Peer Review 26-03-2016,

Acceptance 01-04-2016, Published 29-04-2016.

Corresponding Author:

Dr. Sudhir Sudhakar Pendke,

17, Shastri Layout,

Subhash Nagar,

Nagpur - 440022.

E-mail: sudhirpendke@rediffmail.com

DOI: $10.14260 /$ jemds/2016/464
Our study compares the two procedures and helps us decide if NPGS is truly superior to PGS or merely a modification of the standard procedure without a significant change in results.

\section{MATERIALS AND METHODS}

This hospital based randomised prospective study included 70 eyes with Primary Open Angle Glaucoma in 35 of which non-penetrating Glaucoma Surgery was performed and the remaining 35 underwent penetrating glaucoma surgery in the form of trabeculectomy and all patients were followed up.

\section{Inclusion Criteria}

Patients with Primary Open Angle Glaucoma who gave consent.

\section{Exclusion Criteria}

All patients with any other type of glaucoma. 
Preoperative data included Ocular complaints, BCVA, Intraocular tensions by Perkins applanation tonometer, Diurnal variation test, Slit lamp examination, gonioscopy, perimetry and fundus examination.

The above parameters were reassessed postoperatively after 1 week, 1 month, 3 months, 6 months and 1 year.

Success of surgery was considered as postoperative intraocular pressure less than $21 \mathrm{mmHg}$ in the absence of antiglaucoma medication or other intervention.

Complications such as hyphema, flare, hypotony, shallow or flat anterior chamber, bleb leak, blebitis, macular oedema, maculopathy, choroidal effusion were also looked for.

Surgical Procedure - All surgeries considered in this study were performed by a single experienced senior surgeon. The surgery was preceded by systematic preoperative preparation and was done under peribulbar anaesthesia.

For NPGS, $7 \mathrm{~mm}$ of limbus-based conjunctival flap is made in the upper quadrant. Superficial scleral flap - $5 \times 5 \mathrm{~mm}$ square scleral flap of $40 \%$ depth is dissected up to clear cornea followed by a second $3 \times 3 \mathrm{~mm}$ deep scleral flap of $90 \%$ depth of sclera using a crescent blade. At the level of the scleral spur, the Schlemm's canal is deroofed and a corneoscleral lake is formed to facilitate the diffusion of the aqueous humor. The deep scleral flap is excised along its base $0.5 \mathrm{~mm}$ anterior to Schwalbe's line to create the deep sclerectomy space. Scleral pockets are made on both lateral sides of the deep groove. Superficial scleral flap and conjunctival flap are sutured using 10-0 Nylon sutures.

Trabeculectomy was performed by making a Fornixbased conjunctival incision followed by creating and dissecting a scleral flap. Following this, a deep sclerostomy and peripheral iridectomy were done. Scleral and conjunctival sutures were taken.

\section{OBSERVATIONS AND RESULTS}

From the study of 70 patients surgically treated, the following observations were made: 35 patients of penetrating glaucoma surgery and 35 of non-penetrating glaucoma surgery.

\section{GROUPS DIVISION}

The patients receiving the surgical procedure are divided in two groups.

GROUP A includes patients receiving penetrating glaucoma surgery (Trabeculectomy).

GROUP B includes patients receiving non-penetrating glaucoma surgery (Deep sclerectomy).

\begin{tabular}{|c|c|c|c|c|}
\hline GROUPS & $\begin{array}{c}\text { AGE IN } \\
\text { YEARS } \\
\text { (MEAN } \pm \text { SD) }\end{array}$ & MEN & WOMEN & $\begin{array}{c}\text { PREOPERATIV } \\
\text { E IOP } \\
\text { (MEAN } \pm \text { SD) } \\
\text { in mmHg }\end{array}$ \\
\hline $\begin{array}{c}\text { GROUP } \\
\text { A }\end{array}$ & $61.03 \pm 5.06$ & 20 & 15 & $31.09 \pm 7.36$ \\
\hline $\begin{array}{c}\text { GROUP } \\
\text { B }\end{array}$ & $61.66 \pm 5.29$ & 19 & 16 & $29.26 \pm 7.09$ \\
\hline \multicolumn{4}{|c|}{ Table 1: Age, Sex, Preoperative IOP Distribution } \\
\hline
\end{tabular}

$\mathrm{p} 1=0.61, \mathrm{p}>0.05$, Not Significant. $X^{2}=0.057, \mathrm{p}>0.05$, Not Significant. $\mathrm{p} 2=0.29, \mathrm{p}>0.05$, Not Significant.

Table 1 gives age and sex distribution of patients taken up for the study along with average preoperative IOP of both the groups. No statistically significant difference was seen in any of the above data in the two groups.

\begin{tabular}{|c|c|c|c|c|c|}
\hline Groups & Same & Increase & $\begin{array}{c}\text { Decline by } 1 \text { Line of } \\
\text { Preoperative Level by Snellen's } \\
\text { V/A Testing Chart }\end{array}$ & $\begin{array}{c}\text { Decline by } 2 \text { Lines of } \\
\text { Preoperative Level by Snellen's } \\
\text { V/A Testing Chart }\end{array}$ & Total \\
\hline GROUP A & $25(71.43 \%)$ & - & $7(20 \%)$ & $3(8.57 \%)$ & 35 \\
\hline GROUP B & $23(65.71 \%)$ & - & $8(22.86 \%)$ & $4(11.43 \%)$ & 35 \\
\hline
\end{tabular}

$\mathrm{X}^{2}=0.29, \mathrm{p}>0.05$, Not Significant.

Table 2 shows that maximum number of patients had BCVA same as preoperative at 12 months of followup postoperatively, out of 35 patients in group A $25(71.43 \%)$ patients and in group B $23(65.71 \%)$ patients have same visual acuity as preoperative and that there was no statistically significant difference observed between two groups ( $p>0.05)$. Success of procedure was defined as postoperative IOP less than or equal $21 \mathrm{mmHg}$ without any use of local or systemic antiglaucoma medication.

\begin{tabular}{|c|c|c|c|c|}
\hline & GROUP A (MEAN IOP \pm SD) in mmHg & GROUP B (MEAN IOP \pm SD) in mmHg & P VALUE & S/NS \\
\hline Preoperative & $31.09 \pm 7.37$ & $29.26 \pm 7.10$ & 0.29 & NS \\
\hline POST-OP DAY 1 & $11.23 \pm 3.35$ & $12.03 \pm 4.64$ & 0.41 & NS \\
\hline POST-OP DAY 3 & $11.23 \pm 3.34$ & $12.03 \pm 4.64$ & 0.41 & NS \\
\hline POST-OP DAY 7 & $11.37 \pm 3.61$ & $12.77 \pm 4.72$ & 0.15 & NS \\
\hline POST-OP DAY 15 & $13.37 \pm 3.65$ & $14.29 \pm 4.50$ & 0.35 & NS \\
\hline POST-OP 1 MONTH & $14.2 \pm 3.51$ & $15.2 \pm 5.23$ & 0.35 & NS \\
\hline POST-OP 3 MONTHS & $15.31 \pm 4.03$ & $16.23 \pm 6.55$ & 0.48 & NS \\
\hline POST-OP 6 MONTHS & $15.17 \pm 3.54$ & $16.11 \pm 6.08$ & 0.43 & NS \\
\hline POST-OP 9 MONTHS & $14.97 \pm 3.10$ & $14.86 \pm 4.22$ & 0.89 & NS \\
\hline POST-OP 12 MONTHS & $15 \pm 3.06$ & $14.85 \pm 4.22$ & 0.87 & NS \\
\hline \multicolumn{2}{|r|}{ Table 3: Postoperative IOP Control Comparison Between Two Groups } & \multicolumn{2}{c}{} \\
\hline
\end{tabular}

$\mathrm{p}>0.05$, Not Significant. 
As seen in Table 3, postoperatively there is significant reduction of IOP as compared to preoperative by both the procedures in both the groups.

At 1 month postoperatively, two patients in group B were having IOP $>21 \mathrm{mmHg}$, requiring antiglaucoma medication and one among them required resurgery at 3 months due to non-control of IOP by antiglaucoma medication.

At 12 months of follow-up, mean postoperative IOP in group A was $15 \pm 3.06 \mathrm{mmHg}$ and in group B was $14.85 \pm 4.22$ mmHg. No significant difference between two groups.

It is seen that in postoperative IOP control between two groups, no significant difference was seen between two groups $(\mathrm{p}>0.05)$.

\begin{tabular}{|c|c|c|c|c|}
\hline GROUPS & $\begin{array}{c}\text { PREOPERAT } \\
\text { IVE IOP } \\
\text { (MEAN } \pm \text { SD) }\end{array}$ & $\begin{array}{c}\text { POSTOPERAT } \\
\text { IVE IOP AT } \\
\text { 12 MONTHS } \\
\text { (MEAN } \pm \text { SD) }\end{array}$ & $\begin{array}{c}\text { P } \\
\text { VALUE }\end{array}$ & S/NS \\
\hline GROUP A & $31.09 \pm 7.37$ & $15 \pm 3.06$ & $\begin{array}{c}1.3902 \\
4 \mathrm{E}-15\end{array}$ & $\mathrm{~S}$ \\
\hline GROUP B & $29.26 \pm 7.10$ & $14.85 \pm 4.22$ & $\begin{array}{c}1.6606 \\
4 \mathrm{E}-14\end{array}$ & $\mathrm{~S}$ \\
\hline \multicolumn{6}{|c|}{ Table 4: Preoperative and Postoperative IOP Chart } \\
\hline
\end{tabular}

$\mathrm{p}<0.05$, Significant.

As evidenced in Table 4, for both groups difference was statistically significant, i.e. postoperative IOP significantly decrease from preoperative level $(\mathrm{p}<0.05)$.

\begin{tabular}{|c|c|c|}
\hline \begin{tabular}{|l} 
COMPLICATIONS \\
\end{tabular} & GROUP A & GROUP B \\
\hline \multicolumn{3}{|l|}{ INTRAOPERATIVE COMPLICATIONS } \\
\hline 1. Conjunctival Button Hole & $\begin{array}{c}1 \\
(2.86 \%)\end{array}$ & - \\
\hline 2. Intraoperative Hyphema & $\begin{array}{c}2 \\
(5.71 \%)\end{array}$ & - \\
\hline $\begin{array}{l}\text { 3. Trabeculo-descemet's Membrane } \\
\text { perforation/Internal Iris } \\
\text { Incarceration }\end{array}$ & - & $\begin{array}{c}1 \\
(2.86 \%)\end{array}$ \\
\hline \multicolumn{3}{|l|}{ POSTOPERATIVE COMPLICATIONS } \\
\hline 4. $\quad$ BLEB LEAK -EARLY-LATE & - & - \\
\hline 5. Shallow Anterior Chamber & $\begin{array}{c}9 \\
(25.71 \%)\end{array}$ & - \\
\hline $\begin{array}{l}\text { 6. Postoperative Hyphema/Flare in } \\
\text { Anterior Chamber }\end{array}$ & $\begin{array}{c}3 \\
(8.57 \%) \\
\end{array}$ & - \\
\hline 7. Postoperative Hypotony & - & - \\
\hline $\begin{array}{ll}\text { 8. } & \text { Choroidal Detachment/Choroidal } \\
\text { Effusion }\end{array}$ & - & - \\
\hline 9. Macular Oedema/Maculopathy & - & - \\
\hline $\begin{array}{l}\text { 10. Postoperative Cataract-formation- } \\
\text { Progression }\end{array}$ & $5(14 . \overline{29 \%})$ & $\begin{array}{c}- \\
2 \\
(5.71 \%)\end{array}$ \\
\hline 11. Infection/Blebitis & - & - \\
\hline 12. Endophthalmitis & - & - \\
\hline 13. Failure of Filtration & $\begin{array}{c}2 \\
(5.71 \%) \\
\end{array}$ & $\begin{array}{c}10 \\
(28.57 \%)\end{array}$ \\
\hline TOTAL & $\begin{array}{c}22 \\
(62.86 \%)\end{array}$ & $\begin{array}{c}13 \\
(37.14 \%)\end{array}$ \\
\hline
\end{tabular}

\section{COMPLICATIONS CHART}

\begin{tabular}{|c|c|c|}
\hline GROUPS & $\begin{array}{c}\text { NUMBER OF } \\
\text { PATIENTS WITH } \\
\text { COMPLICATIONS }\end{array}$ & \% COMPLICATIONS \\
\hline GROUP A & 22 & $62.86 \%$ \\
\hline GROUP B & 13 & $37.14 \%$ \\
\hline
\end{tabular}

$\mathrm{X}^{2}=4.62, \mathrm{p}<0.05$, Significant.
Table 5 reveals that in total in group A 22 (62.86\%), patients have complications as compared to 13 (37.14\%); patients in group B have complications and the difference was statistically significant, i.e. there is significant difference in complications between two groups and group B has significantly less number of complications than group A $(\mathrm{p}<0.05)$.

\begin{tabular}{|c|c|c|c|}
\hline GROUPS & $\begin{array}{c}\text { SUCCESS } \\
\text { RATE n (\%) }\end{array}$ & $\begin{array}{c}\text { FAILURE } \\
\text { RATE n (\%) }\end{array}$ & $\begin{array}{c}\text { TOTAL n } \\
\text { (\%) }\end{array}$ \\
\hline GROUP A & $33(94.29 \%)$ & $2(5.71 \%)$ & $35(100 \%)$ \\
\hline GROUP B & $25(71.43 \%)$ & $10(28.57 \%)$ & $35(100 \%)$ \\
\hline \multicolumn{4}{|c|}{ Table 6: Efficacy of Procedure } \\
\hline
\end{tabular}

$\mathrm{X}^{2}=6.43, \mathrm{p}<0.05$, Significant.

As per Table 6 in regard to failure rate, the difference was statistically significant, i.e. group A has significantly less failure rate than group $B(p<0.05)$.

\section{RESULTS}

With regards to age and sex, there was no statistically significant data. Studies including those by Ates $\mathrm{H}$ et al 2001.[1] Bonilla R et al 2012.[2] Dahan et al 2003.[3] Devloo et al 2005.[4] Hamel et al 2001.[5] Sanchez et al 1996.[6] Loscos J et al[7] Loscos-Arenas J et al[8] Greifner $\mathrm{G}$ et al[9] and most others indicate that the preoperative IOP taken for our study falls in the same range as that taken in other similar studies. Also the average age range in our study vs similar studies and within the three groups in our study are statistically insignificant.

In terms of visual acuity, maximum number of patients in both groups have same postoperative BCVA as compared to preoperative, i.e. $20(57.14 \%)$ patients in group A and 21 $(60 \%)$ patients in group B have same postoperative visual acuity as preoperative.

In postoperative BCVA at day one, there was no statistically significant difference observed between two groups $(\mathrm{p}>0.05)$.

Maximum number of patients have BCVA same as preoperative at 12 months of followup postoperatively, out of 35 patients in group A $25(71.43 \%)$ patients and in group B $23(65.71 \%)$ patients have same visual acuity as preoperative.

At 12 months of followup in group A, 7 (20\%) patients had decline by 1 line and $3(8.57 \%)$ patients had decline by 2 lines of Snellen's V/A testing chart due to failure of surgery and postoperative cataract progression.

At 12 months of followup in group B, 8 (22.86\%) patients had decline by 1 line and $4(11.43 \%)$ patients had decline by 2 lines of Snellen's V/A testing chart due to failure of surgery and postoperative cataract progression.

In postoperative BCVA at 12 months, there was no statistically significant difference observed between two groups ( $\mathrm{p}>0.05$ ).

Postoperatively, there is significant reduction of IOP as compared to preoperative by both the procedures in both the groups. Also, the mean percentage reduction in IOP at 12 months for both groups was comparable to newer studies such as that by Gesser $C$ et al.[10] Postoperative on day 1 , mean IOP in group A was $11.23 \pm 3.35 \mathrm{mmHg}$ which is $63.87 \%$ reduction in preoperative IOP, while in group B it was 12.03 $\mathrm{mmHg}$ which is $58.88 \%$ reduction in preoperative IOP. 
There was no statistical significant difference between the two groups.

At 1 month, mean postoperative IOP in group A was $14.2 \pm 3.51 \mathrm{mmHg}$ and in group B was $15.2 \pm 5.23 \mathrm{mmHg}$ and two patients in group B were having IOP $>21 \mathrm{mmHg}$, requiring antiglaucoma medication and one among them required resurgery at 3 months due to non-control of IOP by antiglaucoma medication.

At 6 months of follow-up, mean postoperative IOP in group A was $15.17 \pm 3.54 \mathrm{mmHg}$, while in group B mean postoperative IOP was $16.11 \pm 6.08 \mathrm{mmHg}$ and four patients has IOP $>21 \mathrm{mmHg}$ failure of surgery required postoperative antiglaucoma medication. No significant difference in two groups.

At 12 months of follow-up, mean postoperative IOP in group A was $15 \pm 3.06 \mathrm{mmHg}$ and in group B was $14.85 \pm 4.22$ mmHg. No significant difference between two groups.

It is seen that in postoperative IOP control between two groups, no significant difference was seen between two groups ( $\mathrm{p}>0.05)$.

For group A, mean preoperative IOP was $31.09 \pm 7.37$ mmHg and postoperative mean IOP at 12 months of follow-up was $15 \pm 3.06 \mathrm{mmHg}$. There was statistically significant difference between preoperative and postoperative IOP control.

For group B, mean preoperative IOP was $29.26 \pm 7.10$ $\mathrm{mmHg}$ and postoperative mean IOP at 12 months was $14.85 \pm 4.22 \mathrm{mmHg}$, difference was statistically significant, i.e. postoperative IOP significantly decrease from preoperative level $(\mathrm{p}<0.05)$.

For group A according to IOP range $20-30 \mathrm{mmHg}$, mean preoperative IOP was $25.17 \pm 2.43 \mathrm{mmHg}$ and mean postoperative IOP was $12.5 \pm 1.81 \mathrm{mmHg}$. There is $50.34 \%$ reduction in IOP postoperatively.

In range 31-40, preoperative mean IOP was $34.09 \pm 3.05$ $\mathrm{mmHg}$ and postoperative IOP was $17.18 \pm 2.90 \mathrm{mmHg}$ with $49.60 \%$ reduction in IOP.

In range 41-50, preoperative mean IOP was $43.33 \pm 2.25$ $\mathrm{mmHg}$ and postoperative IOP was $20.67 \pm 3.88 \mathrm{mmHg}$ with $52.32 \%$ reduction.

From the chart, it is seen that there is approximately constant reduction in all ranges of IOP in group A and there is significant reduction of postoperative IOP from preoperative level $(\mathrm{p}<0.05)$.

For group B according to IOP range $20-30 \mathrm{mmHg}$, mean preoperative IOP was $23.74 \pm 2.26 \mathrm{mmHg}$ and mean postoperative IOP was $12.26 \pm 4.03 \mathrm{mmHg}$ with $48.36 \%$ reduction in IOP.

In range $31-40 \mathrm{mmHg}$, mean preoperative IOP was $33.09 \pm 2.98 \mathrm{mmHg}$ and mean postoperative IOP was $19.64 \pm 5.07 \mathrm{mmHg}$ with $40.65 \%$ reduction in IOP.

In range $41-50 \mathrm{mmHg}$, mean preoperative IOP was $41.8 \pm 1.10 \mathrm{mmHg}$ and mean postoperative IOP was $29.17 \pm 2.86 \mathrm{mmHg}$ with $30.14 \%$ reduction.

It is seen from the IOP chart that for group B, there is better postoperative IOP control in lower preoperative ranges as compared to higher preoperative range which has only $30.14 \%$ of reduction in IOP. There is significant reduction in postoperative IOP from preoperative level $(\mathrm{p}<0.05)$.

In group A intraoperatively $1(2.86 \%)$ patient has conjunctival buttonhole and $2(5.71 \%)$ patients have intraoperative hyphema and in group B 1 (2.86\%) of patient has trabeculo-descemetic membrane rupture.

Postoperative complication - in group A 9 (25.71\%) patients have postoperative shallow anterior chamber and 3 $(8.57 \%)$ have postoperative hyphema. In group A 5 (14.29\%) patients have postoperative cataract progression compared to $2(5.71 \%)$ patients in group B has postoperative cataract progression.

In group A $2(5.71 \%)$ patients had failure of surgery compared to $10(28.57 \%)$ patients in group B had failure of surgery with postoperative IOP $>21 \mathrm{mmHg}$ requiring postoperative antiglaucoma medication and reoperation in such patients, whose IOP is not controlled by antiglaucoma medication. Total in group A, 22 (62.86\%) patients had complications as compared to $13(37.14 \%)$ patients in group $\mathrm{B}$ has complications and the difference was statistically significant, i.e. there is significant difference in complications between two groups and group $B$ has significantly less number of complications than group $A(p<0.05)$.

Ravinet et al 2004.[11] in their study diagnosed surgery related complication including positive Seidel test, hyphema, choroidal detachment and iris incarceration. Ates $\mathrm{H}$ et al, 2001.[1] in their study showed no anterior segment complications and as a complication one case of self-limited shallow choroidal detachment was seen. Bonilla $\mathrm{R}$ et al 2012.[2] noted the only intraoperative complication was the microperforation of trabeculo-descemetic membrane in four patients. Drosum L 2003.[12] in their study noted that there were no complications related to hypotony or other significant complications.

Total cases of postoperative success rate, i.e. patients with postoperative IOP $\leq 21 \mathrm{mmHg}$ without antiglaucoma medication or any intervention in group A was $33(94.2 \%)$ and in group B was 25 (71.43\%).

Failure rate, i.e. patients with postoperative IOP $>21$ mmHg in group A was $2(5.71 \%)$ and in group B was 10 $(28.57 \%)$. The difference was statistically significant, i.e. group A has significantly less failure rate than group B $(\mathrm{p}<0.05)$.

Another very important consideration is the cost effectiveness of the procedures. Tan JC and Hitchings RA 2001.[13] state that in deep sclerotomy, the adjunctive implant is priced at approximately $£ 120$. Wang NL 2005.[14] et al have documented that cost of NPTS remains a serious concern. Guedes RAP et al 2011.[15] reported that cost of nonpenetrating deep sclerotomy cost between US \$305.25 to US \$ 390.09 depending on the severity of glaucoma. Thus, these procedures are as or more cost effective than other options in primary open angle glaucoma seen in the study by Ting NS et al.[16]

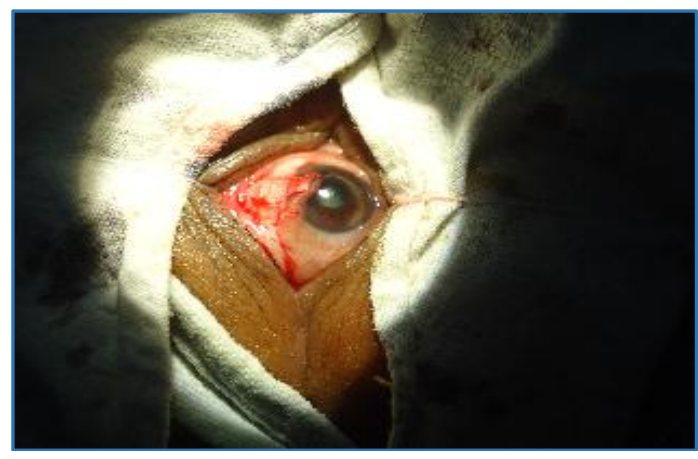

Fig. 1: Creating Superficial Scleral Flap 


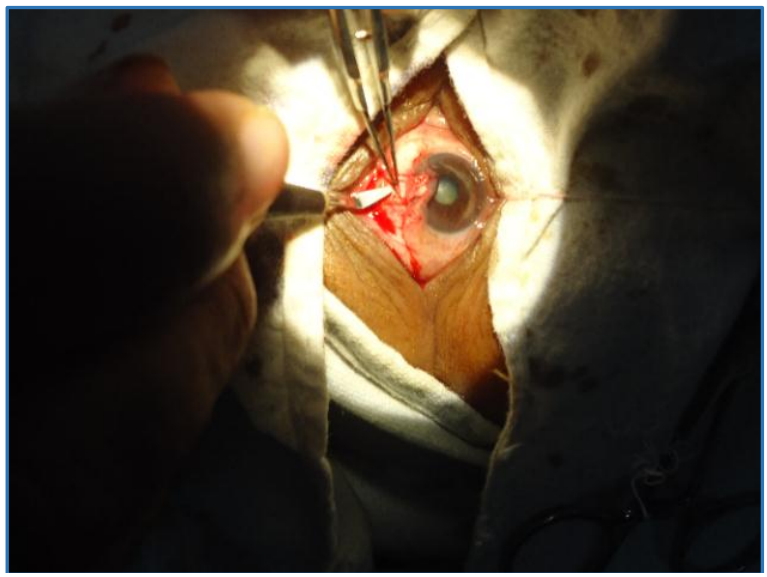

Fig. 2: Creating Deep Scleral Flap

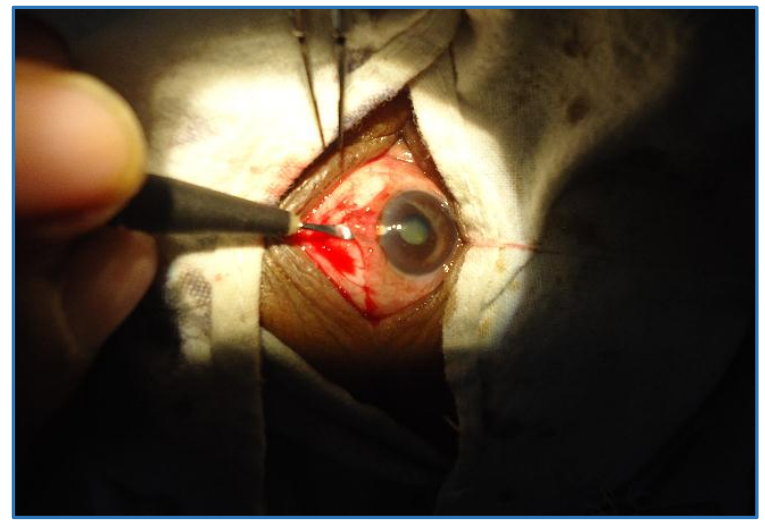

Fig. 3: Creating Clear Corneal Lake

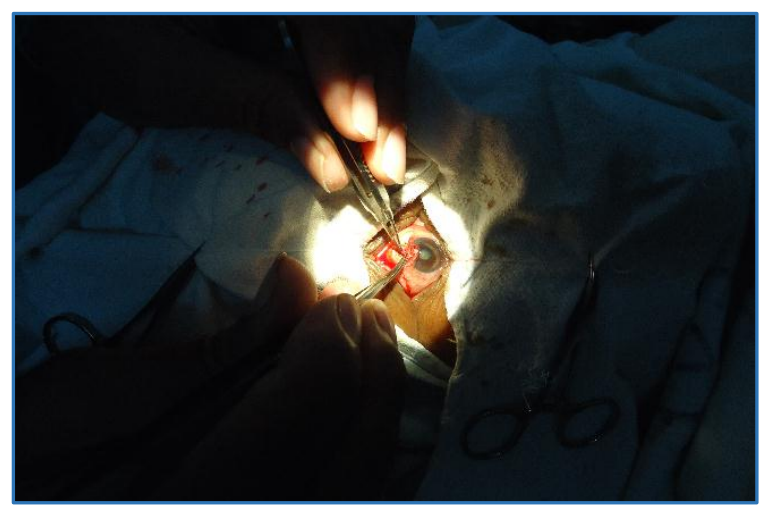

Fig. 4: Cutting of Deep Scleral Flap

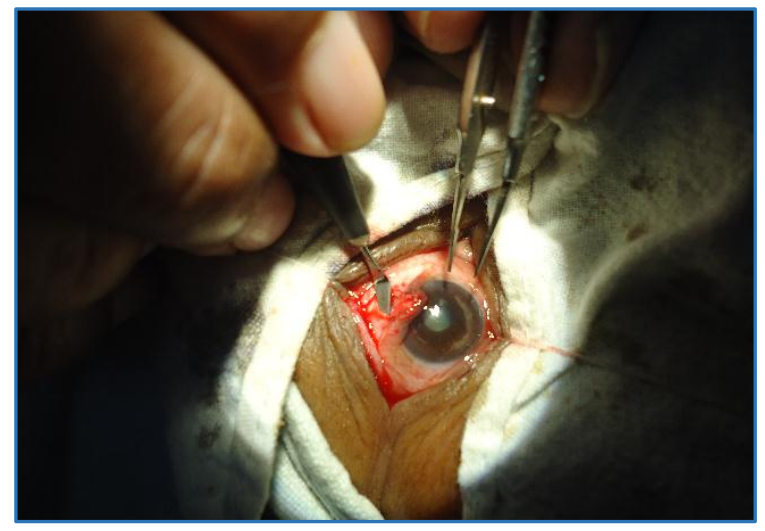

Fig. 5: Deroofing of Schlemm's Canal

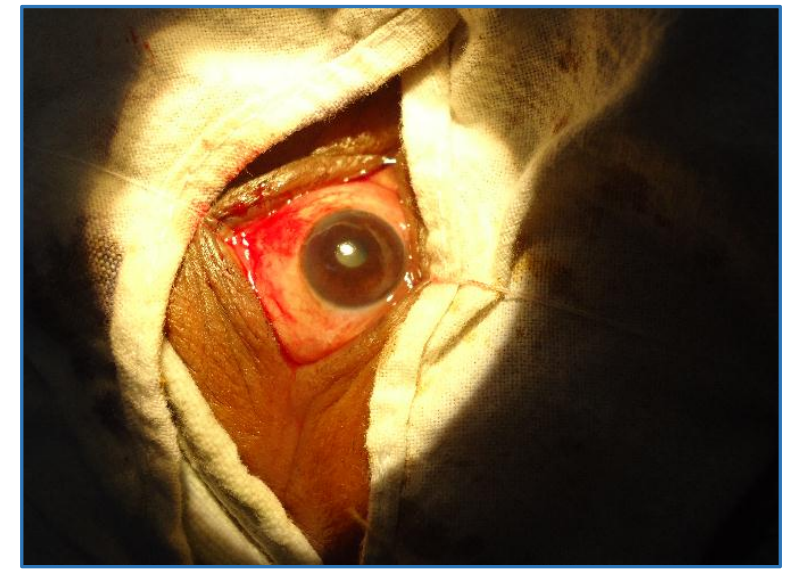

Fig. 6: Reposition of Deep Scleral Flap and Conjunctiva at the End

\section{CONCLUSION}

Our study is a pilot study comparing trabeculectomy against NPGS, which indicates that even though penetrating glaucoma surgery is a more efficacious procedure, complication rates are lesser with NPGS. The most important conclusion that can be derived is that for preoperative intraocular pressures between 21 to $30 \mathrm{mmHg}$, NPGS should be the surgery of choice considering its equal efficacy in this condition and better safety under this condition. Further wide scaled studies must be carried out to confirm or refute these findings and conclusions and establish the exact role of NPGS in treatment of Primary Open Angle Glaucoma.

\section{REFERENCES}

1. Ates $\mathrm{H}$, Andac $\mathrm{C}$, Uretmen 0 . Non penetrating deep sclerectomy and implant surgery in glaucoma patients with advanced field loss. Internal Ophthalmology 2001;23:123-8.

2. Bonilla R, Loscos J, Valldeperas X, et al. Supracilliary hema implant in combined deep sclerectomy and phacoemulsification: one year results. Open Ophthalmol J 2012;6:59-62.

3. Dahan E, Ravinet E, Ben-Simon GJ, et al. Comparison of the efficacy and longeivity of nonpenetrating glaucoma surgery with and without a new, non absorbable hydrophilic implant. Ophthalmic Surg Lasers imaging 2003;34(6):457-63.

4. Devloo S, Deghislage C, Van Malderen L, et al. Non penetrating deep sclerectomy without or with autologous scleral implant in open angle glaucoma: medium-term results. Graefes Arch Clin Exp Ophthalmol 2005;243(12):1206-12.

5. Hamel M, Shaarawy T, Mermoud A. Deep sclerectomy with collagen implants in patients with glaucoma and high myopia. J Cataract Refract Surg 2001;27(9):1410-7.

6. Sanchez E, Shnyder CC, Sickenberg M, et al. Deep sclrectomy: results with and without collagen implant. Int Ophthalmol 1996-1997;20(1-3):157-62.

7. Loscos J, Valldeperas $\mathrm{X}$, Langhor $\mathrm{K}$, et al. Deep sclerectomy with supraciliaryhema implant (Esnoper(®)V-2000): results and complications. Int Ophthalmol 2015;35(5):693-9. doi: 10.1007/s10792015-0037-y. 
8. Loscos-Arenas J, Parera-Arranz A, Romera-Romera P, et al. Deepsclerectomy with a new nonabsorbableuveoscleral implant (esnoper-clip): 1year outcomes. J Glaucoma 2015;24(6):421-5. doi: 10.1097/IJG.0000000000000253.

9. Greifner G, Roy S, Mermoud A. Results of CO2 laserassisted deep sclerectomy as compared with conventional deepsclerectomy. J Glaucoma 2014.

10. Gesser C, Wiermann A, Keserü M, et al. Long-term follow-up after deep sclerectomy. Klin Monbl Augenheilkd 2014;231(5):535-9. doi: 10.1055/s-00331360380.

11. Ravinet E, Bovey E, Mermoud A. T-flux implant versus healon GV in deep sclerectomy. J Glaucoma 2004;13(1):46-50.

12. Drolsum L. Conversion from trabeculectomy to deep sclerectomy prospective study of the first 44 cases. J cataract refract Surg 2003;29(7):1378-84.
13. Tan JC, Hitchings RA. Non penetrating glaucoma surgery: the state of play. $\mathrm{Br} \mathrm{J}$ Ophthalmol 2001;85(2):234-7.

14. Wang NL, Liang $\mathrm{YB}$, Zhuang $\mathrm{XM}$, et al. The early postoperative complications and cost effectiveness analysis os non penetrating trabecular surgery in patients with primary open angle glaucoma. Zhonghua Yan Ke Za Zhi 2005;41(6):505-10.

15. Guedes RA, Guedes VM, Chaoubah A. Resources use, costs and effectiveness of non penetrating deep sclerectomy according to glaucoma stage. Arq Bras Oftalmol 2011;74(6):400-04.

16. Ting NS, Li Yim JF, Ng JY. Different strategies and costeffectiveness in the treatment of primary open angleglaucoma. Clinicoecon Outcomes Res 2014;6:52330. doi: 10.2147/CEOR.S30697. 